\title{
Characterization of TiAl diffusion bonds using Ni/Ti nanolayers
}

\author{
Sónia Simões ${ }^{1}$, Filomena Viana ${ }^{1}$, Ana Sofia Ramos $^{2}$, Maria Teresa Vieira ${ }^{2}$ and Manuel F.Vieira ${ }^{1}$ \\ ${ }^{1 .}$ CEMUC, Department of Metallurgical and Materials Engineering, University of Porto, R. Dr. Roberto \\ Frias, 4200-465 Porto, Portugal. \\ 2. CEMUC, Department of Mechanical Engineering, University of Coimbra, R. Luís Reis Santos, 3030- \\ 788 Coimbra, Portugal.
}

TiAl alloys exhibit a range of attractive properties and are good candidates to replace heavier alloys in areas where weight reduction is imperative, as in the transportation industry [1,2]. However, the application of these alloys depends on the development of new joining technologies. Due to the difficulties of joining these alloys, alternative approaches to conventional processes are necessary. Diffusion bonding and brazing are promising joining technologies to bond these alloys. The diffusion bonding with reactive multilayer has been successfully used in previous studies [3,4]. A common feature of these multilayers is the large amount of heat released during the reaction between the layers to form a new phase. Also, its nanometric structure confers an inherent high reactivity and diffusivity.

In this work, a Ni and Ti multilayer is tested in the diffusion bonding of TiAl alloys. Ni and Ti nanolayers, with periods of 30 and $60 \mathrm{~nm}$, were deposited by d.c. magnetron sputtering into TiAl substrates. Joining experiments were performed at 700 and $800{ }^{\circ} \mathrm{C}$ for 60 minutes, in a vertical furnace with a vacuum level better than $3 \times 10^{-4}$ mbar. Applied pressures of 5 to $50 \mathrm{MPa}$ were tested. The microstructure of the crosssections of the bond interface was analyzed by energy dispersive X-ray spectroscopy (EDS) and characterized by scanning electron microscopy (SEM) and transmission electron microscopy (TEM). Crystallographic information of the phases formed at the joining interface was collected by electron backscatter diffraction (EBSD). The mechanical characterization was performed by shear tests.

SEM images of the as-deposited $\mathrm{Ni} / \mathrm{Ti}$ nanolayers (Figure 1) show a multilayer morphology; $\mathrm{Ni}$ and $\mathrm{Ti}$ alternated layers are clearly distinguished. Sound joints are obtained with the Ni/Ti nanolayers, with 30 and $60 \mathrm{~nm}$ of period, at $700{ }^{\circ} \mathrm{C}$ with $50 \mathrm{MPa}$ and $800{ }^{\circ} \mathrm{C}$ with $10 \mathrm{MPa}$. Microstructural characterization of the joints shows that the bonds obtained with the $30 \mathrm{~nm}$ period multilayer present a larger bonded area. The interface could be divided into distinct zones (Figure 2): two other layers (Zones 4 and 3) adjacent to the TiAl alloy and a central one with small grains (Zone 2), this zone is divided in two by a thin layer rich in Ti (Zone 1). EDS chemical composition of the identified zones are listed in Table 1. These results, in conjunction with Ti-Al-Ni phase diagram, indicate that the central region (Zone 2) is composed by TiNi and $\mathrm{Ti}_{2} \mathrm{Ni}$, while the two layers close to $\mathrm{TiAl}$ substrate corresponds to the $\mathrm{TiNi}$ (Zone 3 ) and $\mathrm{AlNi}_{2} \mathrm{Ti}+\mathrm{Ti}_{3} \mathrm{Al}$ (Zone 4) phases. The identification of the phases was confirmed by EBSD analyses. The highest shear strength value was obtained for joint processed at $800^{\circ} \mathrm{C}$ during $60 \mathrm{~min}$ under a pressure of $10 \mathrm{MPa}$ using a multilayer with a period of $30 \mathrm{~nm}$. This was the joint with a larger bonded area [5].

References:

[1] X. Wu, Intermetallics 14 (2006) p. 1114.

[2] H. Clemens and S. Mayer, Advanced Engineering Materials 15 (2013) p. 191.

[3] S. Simões, F. Viana, V. Volker, M. Koçak, A. S. Ramos, M. T. Vieira and M. F. Vieira, Journal of Materials Science 45 (2010) p. 4351. 
[4] S. Simões, F. Viana, A. S. Ramos, M. T. Vieira and M. F. Vieira, Microscopy and Microanalysis 21 (2015) p. 132.

[5] This research is sponsored by FEDER funds through the program COMPETE - Programa Operacional Factores de Competitividade - and by national funds through FCT - Fundação para a Ciência e a Tecnologia -, under the project PEst-C/EME/UI0285/2013.

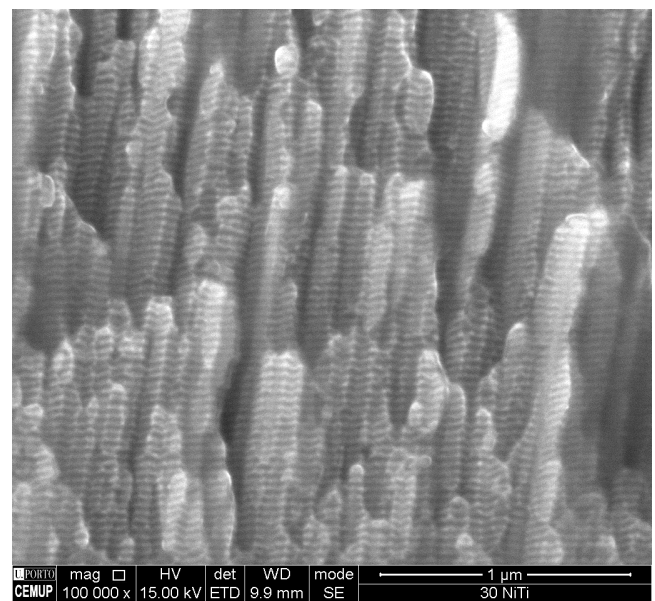

(a)

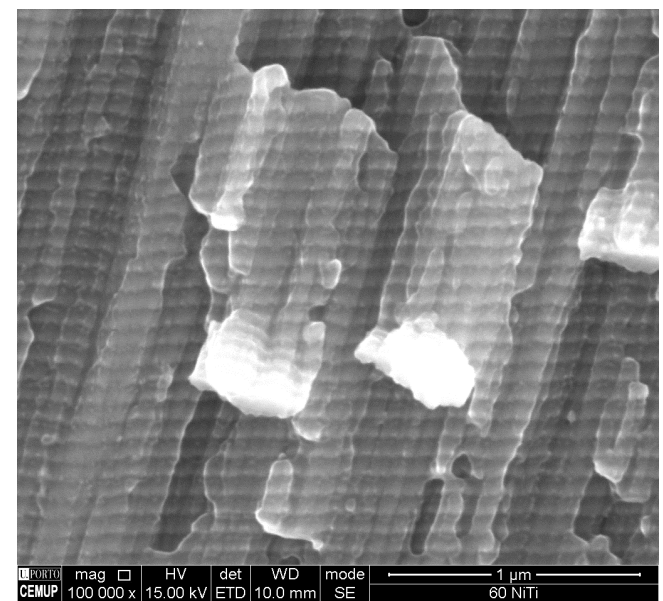

(b)

Figure 1. SEM images of Ni/Ti nanolayers with (a) $30 \mathrm{~nm}$ and (b) $60 \mathrm{~nm}$ of period.

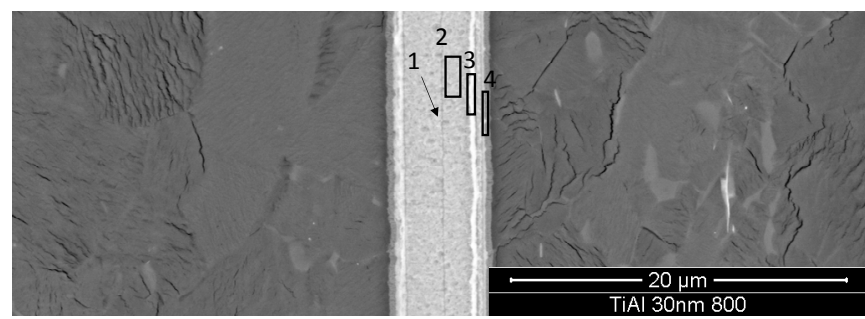

(a)

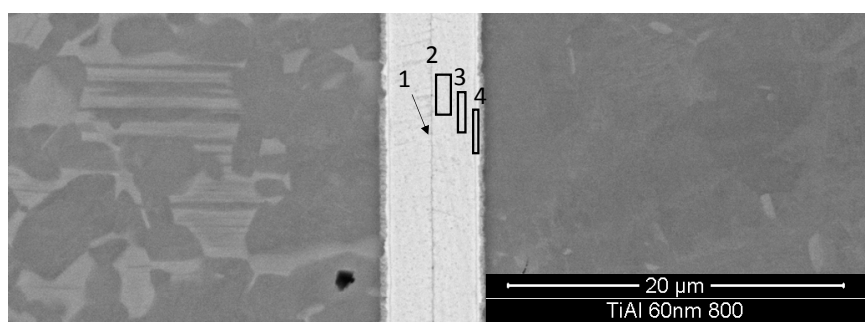

(b)

Figure 2. SEM images of bonding interfaces of TiAl alloys produced at $800{ }^{\circ} \mathrm{C}$ during 60 min under 10 $\mathrm{MPa}$ of pressure with Ni/Ti nanolayers with (a) $30 \mathrm{~nm}$ and (b) $60 \mathrm{~nm}$ period.

Table 1. EDS chemical composition (at.\%) of the different zones (marked in figure 2) of the interface produced at $800{ }^{\circ} \mathrm{C}$ with nanolayers with 30 and $60 \mathrm{~nm}$ of period.

\begin{tabular}{|c|ccccc|ccccc|}
\hline \multirow{2}{*}{ Zones } & \multicolumn{10}{|c|}{ EDS (at. \%) } \\
\cline { 2 - 12 } & \multicolumn{1}{|c|}{$\mathbf{3 0} \mathbf{~ n m}$} & & & \multicolumn{3}{c|}{$\mathbf{6 0} \mathbf{~ n m}$} \\
\hline & $\mathbf{T i}$ & $\mathbf{N i}$ & $\mathbf{A l}$ & $\mathbf{V}$ & $\mathbf{N b}$ & $\mathbf{T i}$ & $\mathbf{N i}$ & $\mathbf{A l}$ & $\mathbf{V}$ & $\mathbf{N b}$ \\
$Z 1$ & 49.8 & 43.8 & 2.1 & 4.3 & - & 49.8 & 43.2 & 1.2 & 5.8 & - \\
$Z 2$ & 47.4 & 46.7 & 2.2 & 3.7 & - & 47.5 & 46.3 & 1.8 & 4.4 & - \\
$Z 3$ & 45.5 & 47.9 & 2.7 & 3.9 & - & 43.7 & 40.5 & 12.7 & 2.3 & 0.8 \\
$Z 4$ & 40.8 & 24.7 & 30.5 & 2.1 & -1.9 & 39.6 & 18.0 & 37.0 & 1.1 & 4.3 \\
\hline
\end{tabular}

